\title{
EXPERIÊNCIAS E PERCEPÇÕES AMBIENTAIS DE MIGRANTES JAPONESES NO SUL DO BRASIL, ANOS 1950 \\ $-1970 *$
}

\section{EXPERIENCES AND ENVIRONMENTAL PERCEPTIONS OF JAPANESE MIGRANTS IN SOUTHERN BRASIL, YEARS 1950-1970}

\author{
André Souza Martinello ${ }^{1}$ \\ Marcos Fábio Freire Montysuma ${ }^{2}$
}

Resumo: Migrantes japoneses em movimentações através dos Estados da região Sul do Brasil (1956-1978) revelam percepções do ambiente, acumuladas na experiência de trato com a terra. A origem no Japão e, a passagem prévia pelo $\mathrm{PR}$ e RS antes de se instalarem em SC, possibilitaram contato com diferentes configurações geográficas, climáticas e culturais, que lhes proporcionaram facilidades na adaptação ao lugar. Por terem exercido agricultura noutros Estados, guardavam informações na memória, que foram úteis para notarem diferenciações em relação aos espaços de terra trabalhados.

Palavras-chave: percepções do ambiente sócio-natural; relação migrante-natureza; migração japonesa.
Abstract: Japanese migrants moving through the states of southern Brazil (1956-1978) reveal perceptions of the environment, accumulated through the experience in dealing with land. The rise in Japan and the previous passage through Parana and Rio Grande do Sul, before settling in Santa Catarina, allowed contact with different geographical, climatic and cultural configurations, which made their adaptation to the place easier. For having practiced agriculture in other states, they had kept in memory information that were useful for noticing differences in relation to areas of worked land.

Keywords: perceptions of the socionatural environment; migrant-nature relations; Japanese migration.

\footnotetext{
* Uma versão diferente desse texto foi apresentada no I Simpósio Internacional de História Ambiental e Migrações na UFSC. Mais informações nos Anais em CD, ISSN 2178-5112 (2010. v. 1. p. 515-536) do mesmo avento.

${ }^{1}$ Mestre em História (UFSC) e Mestre em Desenvolvimento Rural (UFRGS), doutorando em Geografia Humana (USP). andresoumar@yahoo.com.br

${ }^{2}$ Dr. Marcos Fábio Freire Montysuma. Docente na Graduação e Pós-Graduação em História UFSC e no Doutorado Interdisciplinar em Ciências Humanas (CFH/UFSC). mmontysuma@gmail.com
} 


\section{Considerações iniciais}

A proposta deste trabalho está voltada em discutir algumas experiências, apontando maneiras como migrantes japoneses representam cotidianos vividos no ambiente em que se instalaram no transcurso do processo de colonização na região Sul do Brasil. A referência é de migrantes relacionando-se com terras de trabalho. Trata-se do fluxo de japoneses no período de uma década após o fim da segunda guerra. Eram, à época, jovens produtores rurais e mesmo famílias de agricultores que se instalaram em colônias no sul do Brasil, por intermédio do apoio governamental brasileiro (através de instituições estaduais e municipais) e também do governo japonês. Este processo se caracterizou como migração tutelada, ${ }^{3}$ que compreende oferta de financiamento, subsídios e estímulos econômicos para o acesso à propriedade de pequenas parcelas de terra, que formavam núcleo colonial em lotes, com famílias japonesas (medindo em média entre 15 e 25 hectares).

A presente pesquisa está focada na comunidade rural que fora criada nos idos de 1974 a 1975, no município de Criciúma, sul de Santa Catarina, cuja localidade atualmente pertence ao município de Forquilhinha; nomeada e conhecida como Colônia japonesa ou núcleo Sanga Café.

$\mathrm{Na}$ discussão dos relatos de migrantes, consideramos trabalhar com a categoria experiência problematizada na perspectiva de Raymond Williams, ${ }^{4}$ para quem experiência comporta, dentre outras possibilidades historicamente constituídas, o vivenciado pelos sujeitos; e acrescentamos que, o experienciado integra a cultura ordinária dando sentido ao grupo, possibilitando o desenvolvimento da comunidade gregária, fortalecendo os

\footnotetext{
${ }^{3}$ Como bem discutiu Célia Sakurai (2000, p. 202) a imigração japonesa no Brasil: "É tutelada, porque é amparada, desde o início, por meio de orientações, ajudas e gerência dos representantes do governo japonês. A imigração japonesa diferencia-se das outras que escolheram o Brasil, pois se estrutura sobre a cadeia de relações montada a partir do topo da estrutura estatal japonesa até chegar aos imigrantes no Brasil." SAKURAI, Célia. "Imigração japonesa para o Brasil: um exemplo de imigração tutelada (1908-1941)". In: FAUSTO, Boris (Org.). Fazer a América. 2. ed. São Paulo: EdUSP, 2000. p. 201-238. Para o caso mais específico de Santa Catarina ver o artigo: MARTINELLO, André Souza; CARVALHO, Ely Bergo de. "Colonização japonesa em Santa Catarina: metamorfoses na imigração tutelada." Revista História UNISINOS V.15, n.3, (Setembro/Dezembro 2011) pp.543-465. São Leopoldo/RS. doi: 10.4013/htu.2011.153.13

4 WILLIAMS, Raymond. Palavras-Chave - [um vocabulário de cultura e sociedade]; Tradução de Sandra Guardini Vasconcelos. São Paulo: Boitempo, 2007.
} 
sujeitos para enfrentar as intempéries contidas nos desafios cotidianos, na nova terra em que o se instalaram.

$\mathrm{Na}$ realização das entrevistas consideramos as preocupações apontadas por Montysuma ${ }^{5}$ (2006), quando em Um encontro com as fontes em história oral, discute a peculiaridade do trabalho de campo, envolvendo a relação entre o pesquisador e as pessoas que se dispõem a prestar um relato. E como condição de uma metodologia, que lida essencialmente com os sujeitos, são recomendados cuidados, que não são dispensados a nenhuma outra metodologia utilizada por historiadores. Porque qualquer ação excessiva pode provocar danos irreversíveis ao processo de pesquisa em curso. A relação entre as pessoas, no momento da pesquisa, o tempo inteiro é constituído por uma relação em que cada um avalia seu interlocutor, de modo persistente, até se instalar uma possível confiança no diálogo. A partir da sutileza delicada da entrevista, a mesma pode transcorrer sem risco de tensões.

É importante notar que o local em que fora destinado a criação da comunidade era formado por um banhado (uma sanga, sinônimo de arroio) que fora drenado e recebeu bem feitorias como passando por secagem e aterro, visando utilização para agricultura. De área menosprezada pela umidade no solo à terra agricultável, de fato se consumou transformações na área. Esta alteração do solo local, realizado com vista à formação desta colônia, não foi apontada por agricultores entrevistados ${ }^{6}$ como um problema ou obstáculo à produtividade, não interferindo no desempenho do que era ali cultivado, mas visto como uma intervenção humana positiva, uma melhoria. Quando realizamos entrevistas e trabalhos de campo na localidade, em junho de 2006, não havia reclamações por parte dos moradores destas áreas a respeito da transformação das terras da Colônia Sanga Café, em agricultáveis.

Algumas pesquisas das áreas sociais ou dos saberes das humanidades no geral, costumam apresentar peculiaridades de japoneses e descendentes $^{7}$ na interação material que estabelecem com seu entorno e

5 MONTYSUMA, Marcos Fábio Freire. Um encontro com as fontes em história oral. Estudos Ibero-Americanos. PUC/RS, v XXXII, n. 1, p. 117-125, junho 2006.

${ }^{6}$ André Souza Martinello realizou observação com produção de um diário de trabalho de campo, anotando as informações/observações. Entrevistou e conversou com pessoas ligadas à comunidade japonesa do atual município de Forquilhinha, em 12 de junho de 2006, tanto no núcleo urbano do município, como na área rural (na própria colônia localizada: na "Estrada Geral Sanga Café, - Sanga do Café - Forquilhinha/SC"). Entre outras pessoas entrevistadas: senhor Masaru Akaishi, Katsuko Akaishi e Ricardo Fukushima.

7 Destaque para a expressão Nikkei(s), pois é "o termo usado por muitos nipobrasileiros para designar a si próprios; a mesma palavra designa ao mesmo tempo 
meio socioambiental. Em um estudo comparativo entre "pequenos agricultores caipiras e nikkeis", Thaís M. Echeverria ${ }^{8}$ argumenta que mesmo que possa haver diferenças entre brasileiros e nikkeis, no que se refere maior inserção da produção ao mercado, da lógica de agricultura mais racionalizada e a maior capitalização entre nikkeis em relação aos brasileiros, em ambos grupos sociais de uma mesma comunidade a autora encontrou representações sensíveis à natureza. De um ponto de vista de suas atividades produtivas - defende a autora - entre japoneses que são produtores hortigranjeiros e lavradores, eles se identificam a partir de suas relações com o mercado e não com suas relações com a terra. Já no âmbito da vida privada, as representações das famílias japonesas reforçam sentimentos e afetividades compondo a lógica de pertencimento sentimental a terra. Um comentador da pesquisa de Echeverria, argumentou das conclusões do que a autora alcançou, chancelando a existência de representações de natureza entre agricultores descendentes de japoneses:

Em seu estudo sobre agricultores de Piracicaba [SP], fazendo a comparação entre "caboclos" e "japoneses", Thaís Martins Echeverria chama a atenção para como, mesmo entre os floricultores japoneses e niseis fortemente influenciados pelas regras do mercado na orientação de suas estratégias de produção, um código ainda fortemente simbólico e muito tradicional de marcação ritual dos tempos da vida e do trabalho organiza a experiência familiar e comunitária das relações, inclusive com e através da natureza. ${ }^{9}$

Estamos de acordo com a ideia que tanto no Japão, como nas representações ocidentais comumente hegemônicas do oriente e mais ainda a respeito dos imigrantes japoneses que vieram ao Brasil, existe "um apego seletivo è natureza". ${ }^{10}$ Muito se comenta dos ajardinamentos, amor às

descendentes de várias gerações dos imigrantes japoneses”. LESSER, Jeffrey. Uma diáspora descontente: os nipo-brasileiros e os significados da militância étnica 1960-1980. São Paulo: Ed Paz e Terra, 2008.

${ }^{8}$ ECHEVERRIA, Thaís Martins. Caipiras e samurais modernos. Campinas, 1993. 216 págs. Dissertação (Mestrado em Antropologia Social), Instituto de Filosofia e Ciências Humanas/IFCH - UNICAMP. Campinas/SP.

${ }^{9}$ BRANDÃO, Carlos Rodrigues. O afeto da terra: imaginários, sensibilidades e motivações de relacionamentos com a natureza e maio ambiente entre agricultores e criadores sitiantes dos Pretos, nas encostas paulistas da serra da Mantiqueira em Joanópolis. Campinas (SP): Editora da Unicamp, 1999. p. 85.

${ }^{10}$ PONS, Philippe. "Japão: um apego seletivo à natureza." In: BOURG, Dominique. (Org). Os sentimentos da natureza. Lisboa: Instituto Piaget, 1997. pp. 33-49. 
plantas e rituais presentes na paisagem e no ordenamento de vegetais na agricultura realizada entre japoneses. Entretanto, também não é aquele o País em que as Organizações Não-Governamentais/ONG's de preservação ambiental costumam denunciar pelo ainda recorrente extermínio de baleias, por exemplo? Ao estarmos de acordo - para o caso japonês - com a interpretação de um apego selecionado do que se preserva e do que se considera como natureza a ser resguardada, abrimos mão de analisar a nacionalidade como elemento explicativo das maneiras de relacionar-se com a natureza.

Embora nosso texto a seguir, tenha uma interpretação de fundo em que se utilize certo jargão de migração, como a identidade das pessoas ligadas ao Estado nação, afinal, utilizamos, por exemplo, a nomenclatura: "japoneses". ${ }^{11}$ Acreditamos que ao se utilizar a expressão para se referir a alguém enquadrando-a dentro de alguma nacionalidade, já é em parte, legitimar certo tipo de interpretação de cunho nacional. Recusamos de outro lado, a simples interpretação de que o pertencimento, nascimento ou origem em um País (ou local) seja uma explicação automática de determinado comportamento ou vinculo frente à natureza. ${ }^{12}$ Entendemos que é antes a possibilidade de deslocamento, o fator mobilidade tão característico da migração, que permitirá as nossas interpretações das diferentes experiências e compreensões do meio socioambiental dos sujeitos.

\section{Terra de Afeto e Trabalho, valores e sentimentos...}

Estudos das relações entre populações rurais, na construção do meio socioambiental em que se inserem, têm sido realizadas nas ciências sociais e humanas de uma maneira geral. Alguns autores abordaram temas como no contato e comensalismo de estrangeiros, indígenas e colonizadores com espaço tropical, conforme estudado em Caminhos e Fronteiras $^{13}$; a produção dos mínimos vitais por grupos camponeses/caipiras e o contexto

\footnotetext{
11 “[...] em português [do Brasil], não há distinção linguística entre os brasileiros de ascendência japonesa e os habitantes do próprio Japão.” LESSER, Jeffrey. Op.cit. p.21.

12 Para uma boa crítica aos rótulos, expectativas e estereótipos atribuídos à lugares, sociedades e destinos de pessoas, ver: ALBUQUERQUE JÚNIOR, Durval M. de. Preconceito contra a origem geográfica e de lugar: as fronteiras da discórdia. São Paulo: Cortez, 2010.

${ }^{13}$ HOLANDA, Sérgio Buarque. Caminhos e fronteiras. 3. ed. São Paulo: Companhia das Letras, 1994.
} 
de urbanização, como apontado em Os Parceiros do Rio Bonito ${ }^{14}$ e, a própria alteração e impacto às sociedades "autóctones" com a implantação de um modelo largamente de devastação e alteração ambiental da paisagem, pela técnica, economia e poder, em A Ferro e Fogo. ${ }^{15}$ Os estudos e pesquisas das relações antrópicas e impacto da presença humana da transformação da natureza vêm-se ampliando, particularmente na historiografia brasileira. Contudo, para nós, a História Ambiental não é somente e apenas as histórias e narrativas de devastação florestal demonstrando os impactos humanos em seus ambientes, mas também, o vivido, o pensado e os sentimentos em relação à natureza em vínculo com o espaço. Por isso, consideramos importante registrar também, a possibilidade de encontrar o vínculo com o espaço rural ocorrendo a partir de experiências afetivas, segundo entende Carlos Rodrigues Brandão ${ }^{16}$ em um estudo de comunidade realizado em Joanópolis/SP, descritas no livro $O$ afeto da terra.

Nesta mesma direção da interpretação de Carlos Brandão, Ellen e Klaas Woortmann, realizaram pesquisas apresentadas em $O$ trabalho $d a$ terra $^{17}$, apontando como modelos de saberes e de conhecimentos da natureza (por parte de camponeses do nordeste do Brasil) construíam organização de espaços agrícolas e combinações de variedades de plantar, formando ecossistemas em lavouras. Segundo as interpretações destes antropólogos, agricultores realizam percepções da natureza em que interagem. Para os Woortamann, trabalhadores rurais ao realizarem uma dimensão simbólica do trabalho e do saber, constituem espaços sociais e inteligência de modos de cultivar a terra e de tratar a natureza. Para Carlos Brandão ${ }^{18}$, a terra é tributária e resultado de afeto que, afinal, grupos camponeses possuem com ela. Esse antropólogo colheu vários relatos e depoimentos de agricultores acerca da afetividade com o lugar em que vivem e em que produzem alimentos e excedente comercializáveis.

Para Brandão, camponeses tendem a ver (valorar) e relacionar-se com a terra através - entre outras variáveis - do trabalho. Portanto, em sua classificação, este autor afirma que no uso social das terras, camponeses

${ }^{14}$ CANDIDO, Antonio. Os parceiros do Rio Bonito: estudo sobre o caipira paulista e a transformação dos seus meios de vida. São Paulo: Duas Cidades: Ed. 34, 2001. (Coleção Espaço Crítico).

${ }^{15}$ DEAN, Warren. A ferro e fogo: a história e a devastação da Mata Atlântica brasileira. São Paulo: Companhia das Letras, 1996.

${ }^{16}$ BRANDÃO, C. R. 1999. Op.cit. (ver nota rodapé n.8)

17 WOORTMANN, Ellen; WOORTMANN, Klaas. O trabalho da terra: a lógica e a simbólica da lavoura camponesa. Brasília: Editora Universidade de Brasília/UNB, 1997. p. 07.

${ }^{18}$ BRANDÃO, C. R. 1999. Op. cit. 
mais valorizam e possuem afeto com a terra de trabalho, em oposição (conflitiva) as outras diferentes formas sociais e maneiras de lidar com o solo. Brandão relata que também existem na localidade que pesquisou as formas sociais de propriedade e trato: a terra de negócio, a terra de proteção e a terra de lazer. Em estudos em comunidades que realizou no sudeste Brasil, a cultura camponesa tende a dar mais valor e reconhecer a terra que possa ser aplicada seu saber e, através dela, utilizar e dar significados, principalmente, na labuta. É claro também, como lembram Ellen e Klaas Woortmann, que o próprio entendimento e relações de agricultores com a terra alteram-se, pois "As transformações históricas modificaram o espaço rural no qual se moviam os sitiantes, assim como suas percepções." 19

No caso japonês, vale lembrar como a própria delimitação insular e relativa redução do espaço disponível para promover atividades transformadoras da natureza, como agricultura e demais atividades, forçou certo preservacionismo. Menos por planejamento prévio e mais pela não viabilidade geográfica. O difícil acesso, o não alcance social e mesmo reduzida presença de algum recurso o tornaram menos agredido pela complexidade de retirada ou do rápido esgotamento do mesmo. Nas palavras de um especialista, a geografia física das ilhas que formam o Japão ajudam a compreender o por quê de quase um quarto do território japonês ter se mantido intacto da presença humana. Segundo informou devido a não existência de condições de acesso e regular presença humana fixa:

Na relação que uma sociedade mantém com o seu ambiente natural, intervêm três factores: um meio, uma prática cultural e um sistema econômico. Sobre o primeiro factor, podemos assinalar que, por causa do relevo acidentado o essencial da ocupação humana concentra-se nos litorais e em determinadas planícies; neste caso, cerca de $20 \%$ do território nipônico permanecem virgens de qualquer ação humana. ${ }^{20}$

Portanto, o apego seletivo da natureza não é apenas uma questões de desejos de escolha, mas, também de disponibilidade possível.

Nas discussões a seguir, buscaremos correlacionar fatores socioambientais com as práticas culturais e econômicas nas interpretações dos sujeitos. Buscaremos seguir algumas concepções das dinâmicas da natureza que migrantes japoneses e seus descendentes nikkeis realizaram no sul do Brasil, principalmente em Santa Catarina.

${ }^{19}$ WOORTMANN, E.; WOORTMANN, K. Op. cit. p. 27.

${ }^{20}$ PONS, p. 1997, op. cit. p. 33. 


\section{A qualidade do solo e a mediação pela experiência de ser migrante}

É curioso registrar que o espaço, é um elemento fortemente presente no discurso do migrante japonês, Masaru Akaishi, que antes de instalar-se na Colônia Sanga Café em Criciúma, arrendava terras e vivia com seus pais e demais familiares na região de Santana do Livramento, sul do estado do Rio Grande do Sul. A experiência na agricultura na metade sul do estado gaúcho, parece ter contribuído para a subjetividade deste migrante, constituindo sua opinião a respeito da realização de agricultura no sul de Santa Catarina. Quando foi entrevistado, relatou que a entrada no Brasil instalando-se nos rincões gaúchos e "re-migração" para Santa Catarina deveu-se a busca por acesso da propriedade da terra, e que recebeu auxílios para adquirir a mesma, no núcleo Sanga Café, ao qual estava na fase de sua criação/fundação. Mas, relata ainda duas vantagens que o influenciaram neste processo de mudanças, provocando a saída do Rio Grande do Sul em direção à Santa Catarina, primeiro, a qualidade do solo e em segundo, o abrandamento do inverno frio e rigoroso em relação a Santana do Livramento. A respeito da terra na colônia japonesa de Criciúma, o jornal ${ }^{21}$ O'Estado, de julho de 1975, descreveu a opinião do migrante japonês nos seguintes termos: "Masaru Akaishi, 50 anos, 8 meses no núcleo com a esposa e um filho menor, está contente com a qualidade da terra, que 'é bem superior que às áreas arenosas de Livramento (RS)', de onde procede."22

Ainda que o referido jornal, destaque em seu texto a qualidade superior do solo em Santa Catarina em oposição ao do Rio Grande do Sul, podemos atribuir aqui uma primeira ideia que nos aproxima das considerações realizadas pela pesquisadora Maria Isaura Pereira de Queiroz, quando se referia à necessidade de entender a relação humana com o ambiente, para quem temos a expressão da percepção através da experiência do vivido: "[...] os espaços são sempre inseparáveis da percepção que os

21 Observamos que nos jornais pesquisados, como O Estado e a A Gazeta, ambos de Florianópolis, consideram algumas "opiniões" e "relações" de migrantes a respeito do clima e do meio no qual se inseriram, notícias e temas a serem publicados, escritos e levados às letras em suas reportagens. Estamos utilizando as fontes de jornais neste trabalho, conscientes de opiniões como a de Tânia Regina de Luca (2006, p.139), quando afirma que: "[...] a imprensa periódica seleciona, ordena, estrutura e narra, de uma determinada forma, aquilo que elegeu como digno de chegar até o público." LUCA, Tania Regina de. "História dos, nos e por meio dos periódicos." In: PINSKY, Carla B. (organizadora). Fontes Históricas. $2^{\mathrm{a}}$ ed. São Paulo: Contexto, 2006. pp.111-153.

22 Jornal O ESTADO, Florianópolis, 02 de julho de 1975, p. 09. 
capta." ${ }^{23}$ Logo a pessoa não se apresenta apenas como disposta a qualquer custo a permanecer na terra, ela atribui juízos de valor, de aproveitamento, de usos dos bens naturais, para escolher ficar e trabalhar num dado local, e que pode acabar até cultivando uma relação de afeto, como descrito por Brandão. ${ }^{24}$ Porém, podemos dizer mesmo que pode ocorrer também uma relação utilitária que considera a relação investimento/produtividade para aproveitar a terra em seu grau máximo de produtividade. Nesse caso, a migração também pode exprimir uma busca de uma terra que dê retorno ao investimento e trabalho nela aplicado.

Convém considerar aspectos como a confortabilidade das pessoas em relação às questões de caráter climático, onde fazer mais ou menos frio no inverno também parece contar como critério que contribui para que uma dada área de terra seja ocupada ou preterida por uma família migrante. Em nossa interpretação, aspectos como esses transparecerem em fragmentos de jornais, aqui citados; o clima, por exemplo, pode ser, ao menos no discurso, um fator importante como motivador da migração.

Segundo o relato do Sr Masaru Akaishi, as verduras que eram cultivadas em Criciúma, eram favorecidas por um solo muito mais rico do que havia em terras sulriograndenses. Contudo, tal opinião da fertilidade do solo pode ser relacionada com a procedência da pessoa, pois a mesma opinião a respeito da boa qualidade das terras da Colônia Sanga Café não era compartilhada por todos migrantes ali fixados. Vindos do Paraná ou do Rio Grande do Sul, segundo a matéria veiculada no jornal $O^{\prime} E s t a d o$, podemos perceber opiniões opostas conforme segue:

Ao contrário de Masaru, Masato Fukushima, que veio com seus pais e um irmão do Paraná, reclama da qualidade da terra.

- "No Paraná, a terra é tão fértil, que não necessita de fertilizantes. Aqui temos que comprar adubos, o que é muito caro. Lá, toda a família trabalha em terras arrendadas, por isso aceitamos a proposta da Prefeitura de Criciúma."

Masato veio para o Brasil com 19 anos, indo residir, com a família, no Paraná, onde radicou-se. Hoje com 37 anos, confessa não estar muito "contente com a nova situação. No Paraná, mesmo trabalhando em

\footnotetext{
${ }^{23}$ QUEIROZ, Maria Isaura Pereira de. O sitiante tradicional e a percepção do espaço. In: O campesinato brasileiro: ensaio sobre civilização e grupos rústicos no Brasil. Petrópolis (RJ): Ed. Vozes; São Paulo: Ed. Universidade de São Paulo/USP, 1973, p. 69. pp. 48-71. ${ }^{24}$ BRANDÃO, C. R. 1999, op. cit.
} 
terras arrendadas, conseguimos comprar um caminhão e guardar algum dinheiro." 25

Parte das divergências da opinião a respeito das boas terras da comunidade rural se deve então, à experiência anterior, como no caso de migrantes japoneses que tiveram passagem prévia pelo Paraná e consideravam as terras daquela colônia do sul de Santa Catarina de menor qualidade, justamente o inverso do que relatavam os japoneses originários da pampa do Rio Grande do Sul.

Assim, a experiência de trabalhador rural em uma região do Paraná, influenciou a percepção do migrante, a respeito das qualidades da terra da colônia em que veio se fixar, o que nos permite concordar e citar mais uma vez Maria Isaura Pereira de Queiroz, quando muito bem registrou que "Ao contrário do que mostrara Georges Gurvitch, parece-nos que a qualidade do espaço é variável, que este não é forçosamente único.” ${ }^{26}$ Ampla literatura aponta as terras roxas paranaenses como uma das mais férteis do Brasil, nisto a família Masato Fukushima tinha opinião formada por observação direta, uma vez que, argumentaram, não necessitavam de adubos para produzir. Contudo, percebemos que quem lhe recomenda esta distinção entre as terras agricultáveis, de melhor e pior qualidade, não é a experimentação da experiência científica, do laboratório, nem da análise química do estudo de solos, mas é a experiência vivenciada, constituída na prática, no exercício do viver, de haver efetuado plantio, colheita de lavouras no Paraná, por conhecer os processos e o tempo da produção, mas por não deter a propriedade da terra, migrou mais uma vez, agora para Criciúma, onde teve a posse efetiva, adquiriu uma propriedade, via a colonização dirigida, ou migração tutelada. ${ }^{27}$

\section{Migração e relação com o clima, colônias japonesas em Santa Catarina}

Em reportagem sobre a colônia japonesa de Itajaí, publicada no jornal $O$ Estado, de 05 de novembro de 1973, intitulada "Em Rio novo, a terra é boa", o periódico descrevia que em Itajaí

Para japoneses, a terra é fértil: o único inconveniente é o calor. No Japão, o clima é claramente definido em

\footnotetext{
${ }^{25}$ Jornal O ESTADO, 02 de julho de 1975, p. 09.

${ }^{26}$ QUEIROS, op. cit. p.70.

27 MARTINELLO, André Souza; CARVALHO, Ely Bergo de. "Colonização japonesa em Santa Catarina: metamorfoses na imigração tutelada." Op. cit.
} 
períodos frios e quentes e para Fumio Sakuragi, natural da Ilha de Shikoku, no sul do arquipélago nipônico e de clima temperado, o calor compromete bastante a disposição para o trabalho. ${ }^{28}$

Esta é uma primeira representação que os jornais costumavam fazer a respeito das descrições, de como os japoneses interpretavam o clima da colônia em que estavam inseridos, em relação ao Japão. É interessante observar como o clima para alguns é objeto de diferenciação e para outros de aproximação e semelhança ao tipo climático japonês, não havendo uma representação única ou homogênea, ao contrario. Ainda, no caso da comunidade japonesa de Itajaí, vale apontar que, em se tratando de produtores rurais "oriundos de outra cultura", o periódico da capital apontava que havia ocorrido uma diferenciação sociocultural na capacidade de interpretação do clima, entre brasileiros e japoneses (com benefícios, ao "agricultor nacional"). Segundo publicou o jornal $O$ Estado, em reportagem de Raimundo Caruso, os japoneses se sentiam menos preparados e não totalmente capacitados a melhor lidar com a terra em relação aos catarinenses, porque quando chegaram em Itajaí, não conheciam bem os ciclos e estações do ano - o tempo do calendário agrícola - e quase não dominavam ou conheciam o ambiente social, com poucas possibilidades de trocar experiências com os agricultores locais, menos ainda. Estamos diante de uma relação com o espaço que Milton Santos ${ }^{29}$ denominou de alienação: quando o sujeito ignora a historicidade do espaço em que está imerso, suas memórias não o identificam com sua organização, com a distribuição dos seres e dos pertences, na forma como se constam e se encontram em cada lugar, não interagindo ou dialogando completamente com o ambiente em que se localizam.

Num primeiro momento, os migrantes japoneses não tiveram possibilidades de discutir o que produzir para consumidores locais, onde vender, em quais redes e formas de comercializar a produção agrícola, posto que conheciam pouco da dinâmica local:

Se, para os brasileiros, os japoneses tinham hipoteticamente uma vantagem, o do conhecimento milenar da técnica agrícola, por outro lado os orientais

\footnotetext{
${ }^{28}$ Jornal O ESTADO, Florianópolis, 05 de novembro de 1973, p. 04.

${ }^{29}$ Segundo reflexão de Milton Santos (2008, p.328): "Quando um homem se defronta com um espaço que não ajudou a criar, cuja história desconhece, cuja memória lhe é estranha, esse lugar e sede de uma vigorosa alienação." SANTOS, Milton. A Natureza do Espaço: Técnica e Tempo, Razão e Emoção. $4^{a}$ ed. São Paulo: Editora da Universidade de São Paulo/USP, 2008.
} 
declaram que a vantagem no princípio esteve ao lado dos nacionais para melhor que eles, conheciam o produto mais solicitado pelo mercado ao mesmo tempo em que sabiam de antemão as variações do clima que espécies plantar em determinadas épocas. ${ }^{30}$

Contudo, como também descreveu o jornal (ainda em matéria assinada por Raimundo Caruso), bastou menos de um ano para adaptação e aprendizagem de como melhor lidar com as dinâmicas sociais e do ambiente agrícola, tornando o conhecimento semelhante entre japoneses e brasileiros. Para o jornal, além de compartilhar o mesmo pedaço de terra, as diferenças culturais quanto ao conhecimento da relação clima/natureza caíram, e passaram a compartilhar o conhecimento da dinâmica do tempo da natureza: "Porém, como declarou Fumio, agricultor de 39 anos, 'hoje estamos empatados e ninguém pode diferenciar um produto cultivado por um grupo e por outro'." ${ }^{31}$ Quando o migrante japonês declara ao jornalista ter domínio das especificidades climáticas local, do ritmo de produção e melhor conhecer a demanda do consumo, o japonês refere-se como certa superação de um obstáculo, qual seja: o conhecimento e dominação de um espaço. ${ }^{32} \mathrm{O}$ migrante parecia entender que o produto gerado em lavouras e horta de brasileiros e japoneses passava a se tornar iguais, na medida em que japoneses aprendiam a lidar com as estações da natureza, do calendário da plantação e os períodos de melhores cultivos. Era como se a partir da dominação do calendário agrícola anual, os japoneses passassem a ser agricultores competentes e completos, características como veremos mais em frente, nunca atribuídas aos brasileiros pelos jornais da época.

$\mathrm{Na}$ colônia japonesa de Criciúma, o migrante japonês Masaru Akaishi afirmou que veio do sul do Rio Grande do Sul em direção à Santa Catarina, com sua família, porque o frio no estado gaúcho era maior que o frio do Japão. Masaru diz que o a colônia Sanga Café, no sul catarinense, possui um clima muito mais semelhante ao Japão, sendo um frio mais ameno do que ele pode observar e sentir quando viveu no estado gaúcho. $\mathrm{Na}$ entrevista, o migrante japonês, destaca o clima do sul catarinense, como elemento de valor positivo devido semelhança ao clima da região central do Japão, de que era originária sua família, como lembrou senhor Masaru:

\footnotetext{
${ }^{30}$ Jornal O ESTADO, 05 de novembro de 1973, p. 04 (Destaque em negrito nosso).

${ }^{31}$ Jornal O ESTADO, Idem.

32 "Também a cultura é sempre partilha do espaço [...]." BRAUDEL, Fernand. Civilização material, economia e capitalismo: séculos XV-XVIII. O Tempo do Mundo, v. 3. São Paulo: Martins Fontes, 1996, p. 37.
} 
...trabalhamos em uma cidade que fazia divisa com Uruguai, aí nós queríamos nossa terra e também o clima lá era muito frio. Mais frio que o Japão, a gente procurou um clima mais parecido com o Japão. Então veio um dia a JAMIC, ${ }^{33}$ disse que tinha terras e a gente veio para cá. Chegamos aqui em Sanga Café em 1975. ${ }^{34}$

Disse-nos o senhor Masaru, ter migrado ao Brasil em 1952 com seus pais quando estava com aproximadamente cinco anos de idade. A família estabeleceu-se na região extremo sul do Rio Grande do Sul, onde as baixas temperaturas intensas desestimulavam o trabalho agrícola, principalmente no inverno, segundo nos disse o mesmo migrante japonês. Como a sensação de frio apresentava-se maior do que no Japão, segundo Masaru, resolveram buscar suas próprias terras em alguma região de clima mais ameno, conforme fala "um clima mais parecido com o do Japão". Essa fora a explicação dada por Masaru Akaishi, sobre o porquê de fixar-se em 1975 na área rural de Criciúma. A partir da vivência desse migrante, discordamos do historiador Moacyr Flores, ao generalizar a adaptação de nikkeis ao "clima gaúcho" quando afirmou: "Não há dificuldades [dos migrantes japoneses] quanto à adaptação ao clima do Rio Grande do Sul, porque este é semelhante ao sul do Japão [...]"3. 35

Não vem ao caso se o frio era ou não mais forte que o do Japão, em nossa análise importa considerar que na representação deste migrante a situação assim se apresentava nas sensações vivenciadas por ele e por sua família, a ponto de constituir argumentação plausível para justificar a mudança de um estado para outro e corroborar com a idéia de que Santa Catarina era melhor que o Rio Grande do Sul, pelo motivo climático. O clima é usado como legitimador de uma condição de mobilidade e do migrar.

De qualquer maneira, é importante registrar que mesmo havendo referência ao fato de representarem o inverno em Santa Catarina como mais ameno, menos frio em relação ao Rio Grande do Sul, segundo registrou um

33 JAMIC era uma instituição governamental do Japão chamada: "Empresa Japonesa de Migração e Colonização" que atuava na atração e apoio de imigrantes japoneses que se instalaram no estado de Santa Catarina, nas décadas de 1960 e 70 . Atuou em parceria com inúmeras prefeituras e órgãos do governo do Estado e tinha seu escritório regional na cidade de Porto Alegre/RS. Alguns nikkeis fazem referência da JAMIC ter-se tornado a atual JICA/Empresa Japonesa de Cooperação Internacional.

${ }^{34}$ Depoimento de Masaru Akaishi.

35 FLORES, Moacyr. "Japoneses no Rio Grande do Sul”. Veritas, publicação Periódica da Pontifícia Universidade Católica do Rio Grande do Sul (PUC/RS). Porto Alegre, março de 1975. №77, Tomo XX. p. 95. 
periódico em 1975, também ocorreram decepções dos japoneses estabelecidos em Criciúma, pois o frio com ocorrência de geada havia afetado a produção agrícola, causando preocupações aos agricultores. Vejamos em quais termos ocorreram tais registros: "As constantes geadas que vêm caindo nos últimos dias, são motivos de preocupação. Há cerca de dois meses, causaram grandes prejuízos aos agricultores japoneses, queimando várias plantações." ${ }^{36}$ Segundo publicou o jornal, um imigrante japonês fixado em Sanga Café criticou:

"Vim para cá porque, além de deixar as terras arrendadas, onde os vencimentos eram repartidos com o proprietário, disseram que aqui não havia geada. Mas já ouve e foi abaixo de zero, pois queimou até o pimentão. Este tipo de plantação só queima com temperatura inferior à zero." 37

Embora o texto do jornal apresente a situação de um modo bem positivista, em forma de constatação, percebemos ai o conhecimento do agricultor manifestado - claro que pela mediação do periódico - de modo a distinguir o perfil de dano da geada a cada produto plantado, pois acredita diferenciar qual variação de temperatura atinge o pimentão, que é quando baixa de zero grau.

Não somente o frio da região sul do território catarinense fora motivo de "problemas" aos migrantes japoneses. O clima da região meiooeste (planalto), por exemplo, no município catarinense de Curitibanos, foi também motivo de afastamento de migrante japonês que devido às recomendações médicas, deveria mudar do inverno rigoroso e frio de Curitibanos, como parece ter sido fator da saída de japoneses do sul do Rio Grande do Sul. Por outro lado, segundo alguns migrantes nikkeis, o fator climático de temperaturas baixas de algumas regiões de Santa Catarina chegou a ser um das características de atração e vinda de japoneses ligados a agricultura. Portanto, em determinadas regiões o clima de Santa Catarina atraiu migrantes como no caso do litoral, por ser mais ameno em relação ao Rio Grande do Sul.

Nas regiões de maior altitude e menores temperaturas do território catarinense, a atração de japoneses e descendentes se deu justamente pelo frio. Como no caso dos produtores de maçã instalados no município de São Joaquim, que consideraram o clima do planalto extremamente propicio a produção da fruta, e por tal fator, muitos nikkeis, descendentes e filhos de

\footnotetext{
${ }^{36}$ Jornal O ESTADO, 02 de julho de 1975, p. 09.

${ }^{37}$ Idem.
} 
migrantes japoneses, vieram da região de Cotia/SP e estabeleceram-se na localidade, como fruticultores, em pequenas, médias e grandes propriedades. Contudo, é também o clima subtropical (temperado) de temperaturas baixas e sensações gélidas, que possivelmente afastou certa parte de migrantes, mesmo após terem se estabelecidos em propriedades de terras no planalto catarinense, como no caso de Kaneharu Kuroiwa, que solicitou à instituição responsável pelo cadastramento de terras do governo estadual $^{38}$, em setembro de 1981 , a liberação de uma cláusula para vender sua propriedade a Hirotaka Onaka. A solicitação de Kuroiwa, residente no lote número 51 do núcleo Ramos - que à época pertencia a Curitibanos, depois veio a emancipar-se constituindo atualmente o município de Frei Rogério - argumentava problemas de saúde e "por recomendação médica, ter que mudar para uma região em que o clima seja mais quente". ${ }^{39}$ Este é outro exemplo do caso em que o frio foi apontado como fa(r)to, de maneira a influenciar e até impulsionar a migração, estando presente no desejo ou no discurso de (necessidade em) mudar de região, indo em busca de uma área mais quente. Esses são exemplos e casos do clima influenciando em movimentos demográficos e de como também a respeito do clima cunhamse avaliações e adjetivos de bom, melhor, mais saudável, propício, entre outros, seja positivando, seja caracterizando como inapropriado.

\section{A produção de alimentos e o espaço socioambiental. Costumes do que comer}

Ao se entrar em contato com jornais da época da formação da Colônia Sanga Café em Criciúma, observa-se reportagens nos textos dos periódicos, sobre dificuldades de nikkeis encontrarem mercado consumidor para seus produtos horti fruti (seja saladas, verduras), principalmente nos primeiros anos de instalação. Em situação semelhante nas histórias de três núcleos coloniais japoneses em municípios de Itajaí, Caçador e Criciúma, esteve presente a dificuldade de comercialização inicial da produção, apontada como ausência de mercado para consumir aqueles produtos. Sobre

\footnotetext{
${ }^{38} \mathrm{O}$ departamento de registro de terra do Governo do Estado de Santa Catarina sofreu diferentes alterações de seu nome e função, ao longo do século XX. Desde nomes como "Diretoria de Terras e Colonização", passando por "Instituto de Reforma Agrária de Santa Catarina/IRASC" e "Coordenadoria de legitimação e Cadastramento de Terras Devolutas/COLECATE”.

${ }^{39}$ Kaneharu Kuroiwa em correspondência a "Coordenadoria de legitimação e Cadastramento de Terras Devolutas/COLECATE”. Documento pesquisado e disponível no Arquivo Público do Estado de Santa Catarina, caixas do fundo IRASC-COLECATE.
} 
a não existência de "compradores" do que o Núcleo Sanga do Café produziu na época da sua formação, publicou um jornal de 1975:

Acreditando conseguir encontrar colocação para quinhentas caixas de tomate por dia, Masaru, inicialmente, plantou 5 mil pés, que não tiveram mercado consumidor. O mesmo acontecendo com outras plantações.

Concluiu então que terá que diminuir cinco vezes o plantio de cada espécie agrícola, "pois das quinhentas caixas que pretendia vender diariamente, o máximo que consegui foi apenas vinte e cinco, nos mercados de Florianópolis e Porto Alegre, mas os gastos com transporte nos acarretaram prejuízos. Mesmo em terras arrendadas em Livramento, consegui comprar uma kombi e guardar algum dinheiro. Dos treze mil cruzeiros que trouxe, com os gastos no preparo da terra, só me restam mil." 40

É após o maior conhecimento da demanda dos consumidores e das preferências do que comercializar que ocorreu, a superação da dificuldade de não encontrar mercado consumidor. ${ }^{41}$ Entendemos que esta situação pode ser interpretada ao que registra Giralda Seyferth quando aponta, é importante lembrar embora as colônias de pequenas propriedades sejam muitas vezes retratadas como mais autônomas e independentes, não se pode esquecer que estão também submetidos à lógica de mercado, na sua relação de dependência, e acrescentamos, porque não são auto-suficientes. Mas os limites de uma possível auto-suficiência nem sempre é reconhecida no discurso dos migrantes; mesmo que também ocorram trocas e uma organização econômica baseada na moral e na reciprocidade, Seyferth diz que o capitalismo está presente no modo de vida camponês:

A "colônia" (pequena propriedade) é concebida como um microcosmo auto-suficiente na visão dos imigrantes e seus descendentes. Na realidade, trata-se de

\footnotetext{
${ }^{40}$ Jornal O ESTADO, 02 de julho de 1975, p. 09.

${ }^{41}$ Segundo Jornal O ESTADO, Florianópolis, 12 de outubro de 1976, p. 09: "Instalado a 25 quilômetro da cidade, no Distrito de Forquilhinha, o núcleo agrícola Hélio Guerreiro é o único aglomerado de estrangeiros da região e reúne 8 famílias japonesas, que se dedicam à produção de hortaliças. Praticando uma agricultura quase totalmente mecanizada, toda a produção do núcleo é destinada ao mercado consumidor da região, "que já não conseguimos suprir totalmente e muito menos exportar" acentuou o japonês Sakae Fukushima, um dos mais antigos moradores do núcleo. "Isto nos leva a conseguir bons preços pelos produtos" acrescentou."
} 
uma auto-suficiência aparente, pois desde o início estes camponeses estão submetidos às leis do mercado e dependem de atividades externas à comunidade, sejam elas econômicas ou não. ${ }^{42}$

É interessante perceber que, assim como em Criciúma, na colônia japonesa de Itajaí, houve referência semelhante, de que não havia mercado consumidor para os produtos dos migrantes japoneses, como se exprimiu Mitsugi Takahashi, morador do núcleo Rio Novo quando foi entrevistado: "ninguém em Itajaí conhecia nossos produtos quando começamos a comercializar". ${ }^{43}$ Entendemos que a frase não conhecia se aplica em vários sentidos, tanto, por exemplo, não conhecer mesmo, por ser algo novo, e isto afastar as pessoas, por algum tipo de preconceito para com este novo. Outra possível interpretação ao "ninguém" consumia aqueles produtos cultivados pelos japoneses, é a percepção da "regulação" da economia de mercado, baseada na "oferta e procura."

Em Criciúma, quando os japoneses não conseguiram escoar suas produções, segundo reportagem de um jornal de circulação estadual, o problema foi visto, por um migrante, devido ao hábito alimentar dos catarinenses, que diferentes dos gaúchos - segundo publicou o jornal afirmando ser a fala do migrante japonês - "Catarinense não sabe comer, não come verduras, só carne". ${ }^{4}$

\footnotetext{
42 SEYFERTH, Giralda. Imigração e cultura no Brasil. Brasília: editora da Universidade de Brasília/UNB, 1990. p.75

43 Trabalho de campo realizado em 09 de dezembro de 2005, no Núcleo Colonial Rio Novo, comunidade Nikkei de Itajaí, data em que se colheu o depoimento de Mitsugi Takashi.

${ }^{44}$ Jornal O ESTADO, 02 de julho de 1975, p. 09.
} 


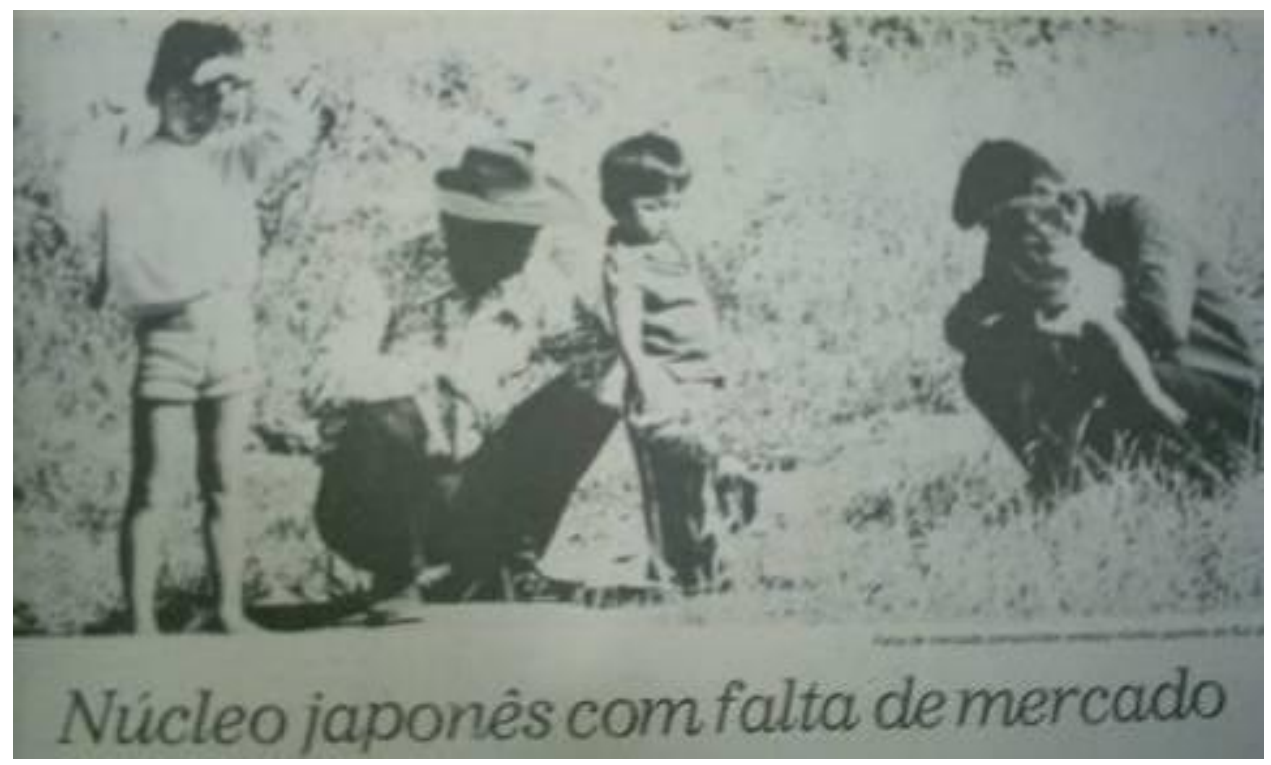

Figura 1: Fotografia publicada no Jornal O Estado, 02/07/1975, noticiando sobre a Colônia Nikkei Sanga Café ${ }^{45}$

Uma criança à esquerda com a mão a testa fazendo sombra, olhando ao horizonte e demais pessoas, membros da colônia japonesa à época da publicação pertencente ao município de Criciúma, atualmente Forquilhinha/SC. Nessa imagem o jornal buscou noticiar a não existência de mercado para o que a comunidade rural produzia, somado com outras dificuldades como as adaptações ao clima e busca por conhecimento das dinâmicas ambientais pelos migrantes.

Os jornais da época também acabavam construindo a ideia de que inicialmente para os japoneses "tudo era problema". Em Criciúma, as dificuldades encontradas nas intempéries do clima, no tipo de solo e na inexistência de mercado consumidor não possibilitaram o progresso "esperado". Enquanto que para os brasileiros instalados na mesma localidade "tudo estava certo", já que para esses o "progresso não viria", os japoneses, ao contrário, eram retratados como realmente preocupados, trabalhadores sérios e como migrantes modelos. Assim descreveu um jornal em 1975, a respeito de uma família de brasileiros no Núcleo Sanga Café:

\footnotetext{
${ }^{45}$ Imagem sem registro de crédito da autoria, publica no Jornal O ESTADO, 02 de julho de 1975, p. 09.
} 
Valmir José Savi e Maria Teresa Savi, formam uma das famílias brasileiras radicadas no Núcleo, onde estão a três meses.

Com seus poucos recursos, ainda estão bastante atrasados em relação ao estágio de desenvolvimento dos japoneses, que chegaram quase na mesma época.

Com alguns pés de repolhos plantados, demonstram estarem satisfeitos com a situação. "Temos um longo prazo para pagar a confiando em Deus, tudo vai dar certo", disse Maria Tereza Savi. ${ }^{46}$

A imagem dos "brasileiros confiantes", tranquilos ou crentes em uma força divina, faz parte de um discurso em que a superioridade é atribuída ao japonês, enquanto que o "brasileiro é o caboclo, considerado preguiçoso, indolente." ${ }^{\prime 7}$ Portanto, estamos diante da construção de estereótipos étnicos e de imagens que representaram os japoneses como trabalhadores, qualificados e racionais, que se "falharam" ou não foram bem sucedidos, a culpa se deve ao meio em que se encontram, muitas vezes ao clima, a qualidade do solo; enquanto que aos brasileiros, ao contrário, recaía a imagem de que estavam "em um estágio de desenvolvimento atrasado", geralmente representação ligada à ideia de que consideram o trabalho degradante.

Em posição oposta a esses preconceitos presentes nos jornais de época, Giralda Seyferth lembra que os intercâmbios entre diferentes etnias e pessoas de diferentes nacionalidades em núcleos coloniais, possibilitaram "assimilações" culturais, que provocariam surgimento de hábitos alimentares, até então não registrados. Caracterizados por originarem-se no convívio e no dia-a-dia, não necessariamente obvio, como nos aponta a citação seguinte, um certo hibridismo cultural na convivência:

Um dos efeitos mais óbvios da colonização foi a mudança dos hábitos alimentares dos imigrantes e dos brasileiros que convivem nas mesmas áreas. A introdução e o consumo de hortaliças, nas cidades e na área rural, são consequências da imigração, seja europeia seja japonesa. ${ }^{48}$

Se as diferentes culturas chegam a alterar os padrões alimentares, também podem - assim como o capitalismo - interferir

\footnotetext{
46 Idem.

${ }^{47}$ SEYFERTH, G., op. cit. p.81.

${ }^{48}$ SEYFERTH, G., op.cit. p.33.
} 
no mercado. Se o mercado interferiu na comercialização e produção japonesa, assim como as intempéries do clima, a cultura também teve seu papel nesse processo. Como estranhou o camponês Masaru Akaishi, segundo o jornal O'Estado de julho de 1975, sobre o padrão alimentar e o comportamento dos catarinenses, quando dizia que catarinenses são sabiam comer, pois não comem verduras, apenas carne, ${ }^{49}$ o jornal chegou a publicar, que a esperança de alguns produtores japoneses estava em vender suas produções agrícolas para o Rio Grande do Sul, pois não parecia ter interesse de consumidores catarinenses. Outra opção seria retornarem para regiões que haviam partido: "Alguns agricultores pensam até mesmo em voltar para as suas terras de origem, apesar de possuir alguma esperança em encontrar mercado para seus produtos no sul, principalmente nos municípios gaúchos." $" 50$

Se em julho de 1975 o jornal O'Estado apontava que não havia mercado para a produção dos migrantes japoneses, no ano seguinte, o mesmo jornal dizia do sucesso dos migrantes e a boa comercialização agroalimentar, percebe-se então uma ruptura. Segundo o jornal, afirmou o migrante japonês Sakae Fukushima fazendo referência à superação da época em que não havia compradores das suas produções:

"Quase não havia mercado consumidor e o produto sobrava, porque ninguém nos conhecia e muito menos interessava-se em adquirir hortaliças. Hoje, felizmente, já somos poucos para abastecer todo o mercado local e temos conseguido grandes lucros. Até mesmo os prejuízos sofridos já foram repostos", salientou Sakae. ${ }^{51}$

Assim, em Criciúma, semelhante ao núcleo japonês de Caçador (alguns documentos denominam Núcleo Paiol Velho), após as primeiras dificuldades em "encontrar" compradores ou consumidores para os produtos agrícolas dos japoneses, o problema deixava de ser a falta de mercado consumidor e passava a ser a falta de mão de obra externa a família, e ao próprio núcleo colonial.

\footnotetext{
49 Jornal O ESTADO, 02 de julho de 1975, p . 09.

${ }^{50}$ Idem.

${ }^{51}$ Jornal O ESTADO, 12 de outubro de 1976, p. 09.
} 
Alegava-se não existirem pessoas disponíveis ao trabalho agrícola. Porém, a solução seria facilmente encontrada na implantação de mais tecnologia, segundo afirmava o produtor japonês, morador da colônia Sanga Café:

Reclamando da carência de mão-de-obra e valorizando a mecanização, Sakae falou da satisfação em cultivar estas terras explicando que "com o tempo estamos conseguindo preparar bem o terreno, à base de fertilizantes, o que vai intensificar a produção. Além das boas condições oferecidas pelas terras, dispomos de uma escola* bem perto - a 200 metros - o que nos dá uma certa tranquilidade, já que nossos filhos poderão estudar aqui mesmo." 52

Neste trecho de jornal citado, é possível encontrar o imaginário de que o agricultor japonês é aquele que está sempre atuando na produção agrícola, com aplicação de elevada quantidade de "fertilizantes" sintéticos, agrotóxicos e outros "biocidades". É preciso enfatizar que a imagem do japonês "ultra-moderno" e destruidor da natureza pela excessiva implantação de "venenos" em suas hortas, é imagem recorrente, inclusive, como se fosse algo típico da "cultura japonesa". Vale lembrar, como fez Giralda Seyferth, que "antes do adubo químico, hoje bastante empregado por pequenos produtores, os japoneses trabalharam com adubo orgânico, animal ou vegetal, como era o caso do feijão mucuna verde". 53

É preciso registrar que a partir do aumento da "consciência ambiental", das pesquisas nas relações agricultura e meio ambiente e das conclusões em relação às consequências negativas de fertilizantes sintéticos, começou-se a reordenar novas formas de produção agrícola. Aquele modelo adotado a partir da década de 1950 e mais ainda em 1960-70, denominado de Revolução Verde, baseava-se em altas taxas de produtividade proporcionadas pela introdução de maquinário, tecnologia, fertilizantes sintéticos, agrotóxicos, água para irrigação artificial, entre outros. Contudo, ao longo do tempo, a

\footnotetext{
* Na entrevista informal com um filho de imigrante japonês, Ricardo Fukushima, nos relatou que a implantação da escola primária no Bairro Sanga Café foi uma reivindicação e um pedido dos colonos japoneses e nikkeis.

52 Jornal O ESTADO, 12 de outubro de 1976, p. 09.

${ }^{53}$ SEYFERTH, G. op.cit. p.39.
} 
Revolução Verde significou alto potencial de impacto destrutivo ambiental e diminuição da capacidade produtiva, devido ao desequilíbrio biológico gerado, causando, inclusive, danos irreversíveis e tanto os migrantes japoneses no Brasil, como muitos descendentes também estiveram presentes na crítica deste tipo de produção. Ao se observar a presença de japoneses e nikkeis na produção orgânica, biológica ou de insumos não-sintéticos, pode-se dizer que há uma carga exagerada e pejorativa ao tratar os japoneses e descendentes como agricultores que mais utiliza inseticida e demais produtos tóxicos à saúde e poluidor do ambiente. Pode-se notar, em jornais do inicio da formação de núcleos coloniais, transcrições de depoimentos de japoneses que afirmavam desejar melhorar a produção e o aumento da mesma, aplicando fertilizantes, mas nem sempre esta referência era esclarecedora se tratava de fertilizantes orgânicos ou sintéticos.

Por outro lado, mesmo o solo do Núcleo Sanga Café sendo considerado de boa qualidade pelo próprio migrante japonês, segundo informava o jornal, ainda sim parecia ser importante aplicação de melhoramentos:

Morando há apenas seis meses, no Sul e falando muito mal o português, a família de Hideo Maeda, 53 anos, que veio do Japão para São Paulo em 1973, dedicando-se à criação de galinhas diz que "quando vim para cá passei a produzir hortaliças e estou bastante otimista com a primeira colheita já que a terra é boa, e com o uso intensivo de fertilizantes, ficará ainda melhor", finalizou. ${ }^{54}$

É preciso lembrar que sendo ou não excessivos utilizadores de inseticidas (sintéticos), para o bem ou para mal, muitos dos migrantes japoneses instalados em colônias em Santa Catarina voltaram-se a produção de alimentos. Em relação à comercialização dessa produção, segundo jornal de outubro de 1976: “-'Os produtos de inverno, como repolho, couve-flor, alface e outros já foram vendidos e só esperamos o crescimento dos produtos típicos de verão, como o

${ }^{54}$ Jornal O ESTADO, 12 de outubro de 1976, p. 09. 
tomate e o pimentão para o início de novas colheitas' - lembrou"55 Sakae.

Como apontamos anteriormente, o migrante acusava a carência de mão-de-obra como problema principal daquele momento "mas justificou afirmando que isto "não importa muito, porque nosso objetivo é mecanizar tudo de uma vez. Atualmente já dispomos de micro tratores e de um caminhão e os lucros da próxima colheita, pensamos aplicar tudo em novos equipamentos". 56 Portanto, podemos considerar a partir da identificação da implantação de métodos "modernos" e convencionais naquelas propriedades, que a denominada modernização agrícola, via Revolução Verde, também estava presente na organização e produção dessa vila e na colonização japonesa em Santa Catarina. Mas isso não implica, necessariamente, em reforçar preconceitos e imagens de japoneses como agricultores poluidores, porque, ultra-modernos. Afinal, não seria também um resultado do "excessivo de modernidade", o surgimento de uma agricultura denominada orgânica, biológica, ecológica etc, em resposta, a agricultura convencional?

Estereótipos em relação aos nikkeis marcam seja por uma verdadeira idealização de naturalmente protetores do ambiente, ou pelo inverso, como se profundos degradadores contumazes do que é natural. Entendemos concepções diferenças dessas, pois encontramos concepções de natureza nas relações que japoneses estabeleceram com solo, terra, propriedade rural, clima e calendário agrícola nos movimentos migratórios que suas experiências vivenciaram.

\section{Considerações finais, ou, Por uma análise da qualidade solo, a partir da experiência dos migrantes}

Encontramos em nossas pesquisas, que migrantes adquirem experiências no trabalho com a terra. Relatam em seus depoimentos os modos como formam valores, sentimentos e afetos com a terra em que se estabelecem. Principalmente quando são proprietários, além de realizarem o trabalho nela, concebem-na como um patrimônio que

\footnotetext{
${ }^{55}$ Idem.

56 Idem.
} 
possa ser deixado a herdeiros e gerações seguintes. Contudo, as classificações e valores em relação à terra, não se dão exclusivamente em opiniões da riqueza ou qualidade do solo, mas também, em comparação com as experiências transcorridas em outras terras, em observações e vivências em outros solos e climas, nos fluxos e movimento migratórios que vivenciaram. Assim, para os migrantes japoneses que antes de acessarem a posse da terra em Santa Catarina, tiveram passagem pelo (norte do) Paraná, Rio Grande do Sul e ao se fixarem nas terras do sul catarinense, alguns diziam ter percebido que não era bom tal solo, nem propício para exercer a agricultura; na verdade eram piores que o solo dos lugares de que migram, no caso, dos vindos do Paraná. Para japoneses e nikkeis, nessas terras em Santa Catarina era necessário usar insumos para proporcionar a fertilidade da mesma, o que não era preciso, no norte paranaense.

Já para os migrantes também originários do Japão que antes de se estabelecerem no sul da Santa Catarina havia trabalho em regiões de fronteira e no pampa do Rio Grande do Sul, as terras catarinenses eram sim um solo fértil e muito mais rico, o que possibilitava melhores cultivos do que em solos gaúchos. Por isso, não é em si, ou somente a qualidade do solo que o define como bom ou não, mas também o olhar, o sentimento e a avaliação lançado sobre ele, sobre essas terras. As experiências como agricultores e migrantes influem na avaliação feita da terra. E vimos também que os jornais buscaram escutar, interpretar e escrever o que os vindos "de fora" achavam a respeito das terras que acabavam de chegar e conhecer. Tentou-se demonstrar aqui, parte das avaliações e dos olhares do solo na Colônia japonesa, Sanga Café, que se deu pela influência da experiência prévia e condição migrante desses japoneses.

É claro que essa condição migrante não se limita apenas na análise ou avaliação do solo, afinal, muitos japoneses também estranharam que mesmo executando em Santa Catarina as "mesmas" produções agrícolas que realizavam no Rio Grande do Sul, não havia interesse inicial da população catarinense para o consumo das suas produções, o que levou um migrante japonês afirmar que catarinense só come carne. $\mathrm{O}$ que em parte é modificado, em menos de um ano, após o inicio da colonização, conforme foi identificado pelos próprios migrantes. Isto foi possível na medida em que se ampliou 
exponencialmente a demanda e o consumo do que era produzido nesta colônia japonesa. Mas o que vale também registrar, mesmo que polêmica é a ideia que há estranhamentos em relação ao clima; na visão de uns o clima era melhor, menos frio, e na opinião de outros era pior, mais frio que o Japão.

Também ocorrem apontamentos quanto às condições socioculturais em que se inseriram e havia relatos descrevendo a precariedade do solo. Por isso, para nós, não há apenas terras ricas, férteis, de melhor ou pior qualidade segundo classificações pedológicas ou agronômicas, há também a ação humana e as avaliações delas, relacionada à capacidade de transformação de acordo com a cultura e a experiência dos sujeitos que interagem.

Nossa pesquisa leva-nos a afirmar que no caso da comunidade nikkei de Sanga Café, é mais o valor da experiência vivida e refletida do migrante que qualifica a terra como boa ou má para agricultura, do que a análise "comprovada" das ciências "exatas" e duras, aquelas de laboratórios. Mas, além disso, para os migrantes japoneses aqui tratados, o solo fora mais do que fértil, ele fora classificado de acordo e em comparação aos solos que haviam trabalhado e realizado a agricultura anteriormente à colonização em Santa Catarina. Como se viu com esta pesquisa, mais do que ricos e férteis, a terra recebe também olhares e valores, classificações de boa ou ruim. É descrita em grau qualitativo e de desempenho, o que para alguns japoneses era terra muito boa e fértil, para outros japoneses, era justamente o inverso.

Mais do que agrônomos, extensionistas rurais e demais estudiosos do solo costumam pensar, a História e a abordagem da historiografia ambiental ajudam muito a explicar as análises acerca da qualidade do solo, segundo aqueles que na terra trabalham e cultivam alimentos. As experiências e condição desses migrantes anterior a instalação no sul catarinense têm muito a dizer também a respeito da riqueza ou não do solo e dos ambientes sociais e naturais da região da Colônia Sanga Café. 